\title{
IDH1 Mutation in Gliomas in Baghdad by Immunohistochemical Study
}

\author{
Zahraa Marwan Shaban ${ }^{1,}$, , Salim Rasheed Al-Aubaidy ${ }^{2}$, Ameer Dhahir Hameedi ${ }^{2}$ \\ ${ }^{1}$ Pathology Department and Forensic Medicine, College of Medicine, University of Mosul, Mosul, Iraq \\ ${ }^{2}$ Pathology Department and Forensic Medicine, College of Medicine, University of Baghdad, Baghdad, Iraq
}

Email address:

zahraamarwan@gmail.com (Z. M. Shaban)

${ }^{*}$ Corresponding author

\section{To cite this article:}

Zahraa Marwan Shaban, Salim Rasheed Al-Aubaidy, Ameer Dhahir Hameedi. IDH1 Mutation in Gliomas in Baghdad by Immunohistochemical Study. International Journal of Genetics and Genomics. Vol. 6, No. 1, 2018, pp. 1-7. doi: 10.11648/j.ijgg.20180601.11

Received: November 7, 2017; Accepted: November 20, 2017; Published: January 11, 2018

\begin{abstract}
I D H 1$ (isocitrate dehydrogenase 1) mutation might be encounter in the low-grade glioma occurs in early stages of development and directs the progression of the tumor to a higher grade. Aim of the study was to assess the frequency of IDHI mutation in Iraqi patients with gliomas by immunohistochemical study, to correlate its immunoreactivity with some clinicopathological parameters. The study did on formalin fixed, paraffin embedded tumor tissue from 66 patients with different grades of intracranial gliomas of both gender and all age groups in the Baghdad city were collected in this retrospective and prospective randomized study. Ten normal brain tissue samples in form of paraffin blocks took from forensic medicine unit. New technique used, which is manual tissue microarray Immunohistochemical detection of IDHI antibodies did by Dako autostainer link 48. Positive cytoplasmic $I D H 1$ staining was found in $38(57.6 \%)$ of cases of glioma. In adult gliomas, secondary glioblastoma multiforme, low grade astrocytoma and oligodendroglial tumors had the greatest values of IDHI positivity $(87 \%, 80 \%$ and $72.72 \%$ respectively) followed by anaplastic astrocytoma (42\%), then primary glioblastoma multiforme (26\%). Males and females expressed the IDH1 equally. The conclusions from the work were IDH1 mutation commonly existed in adult gliomas, low-grade gliomas and secondary glioblastoma, it had no role in pediatric gliomas, and it could be a diagnostic and prognostic marker.
\end{abstract}

Keywords: $I D H 1$, Adults, Pediatric, Manual Tissue Microarray, Glioma, Immunohistochemical Study

\section{Introduction}

Gliomas considered the most common primary malignant brain tumors in adults [1], [2]. The major types of glial tumors are astrocytomas, oligodendrogliomas, and ependymomas [3]. The most common types are highly infiltrative or "diffuse gliomas," including astrocytic, oligodendroglial, and mixed forms. In contrast, ependymomas tend to form solid masses [3].

Gliomas are categorized as grade I to grade IV according to histopathological and clinical criteria established by the WHO [4], [5], [6], [7]. WHO grade I gliomas, have an idle growth, often considered benign, and hardly ever, evolve into higher-grade lesions [7]. By contrast, gliomas of WHO grade II or III are aggressive tumors, usually invasive, diffuse, advance to higher grade (grade III or IV) lesions, and have a poor outcome [7], [8].

Evolution of glioma to a higher grade tumor is multistep process involving many genes and characterized by genetic alterations and mutations accumulation [9]. Recent suggestion proposes that the initiation and progression of gliomas may involve the accumulation of multiple genetic alterations. For example, isocitrate dehydrogenase (IDH1, IDH2) mutations identified in most low grade gliomas, suggesting that $I D H$ mutations are an early event in gliomagenesis [6], [10]. Other genetic abnormalities may accumulate during tumor progression and include $1 \mathrm{p} / 19 \mathrm{q}$ codeletion in oligodendroglial tumors and TP53 mutation or $17 \mathrm{p} 13$ loss in astrocytic tumors [6], [11].

$I D H 1$, which is a member of IDH gene family, located on chromosome $2 \mathrm{q} 33.3$ (the long arm of chromosome 2 at 
position 33 and encodes for the cytosolic NADP+ dependent isocitrate dehydrogenase enzyme [12], [13].

Five genes encode for three human IDH catalytic isozymes; $I D H 1, I D H 2$, and IDH3. IDH1 and 2 form homodimers while $I D H 3$ forms a heterotetramer containing two $\alpha$, one $\beta$, and one $\gamma$ subunit [14], [15]. IDH3 functions in the Krebs cycle to convert isocitrate to $\alpha$-ketoglutarate $(\alpha-\mathrm{KG})$ and NAD+ to NADH [14], [16], [17]. The IDH1 and IDH2 proteins in the cytosol and mitochondria, respectively, generate reduced nicotinamide adenine dinucleotide phosphate (NADPH) from $\mathrm{NADP}+$ by catalyzing the oxidative decarboxylation of isocitrate to $\alpha-\mathrm{KG}$ outside of the Krebs cycle [14], [16], [17], [18]. NADPH mainly produced by glucose 6-phosphate dehydrogenase $(\mathrm{G} 6 \mathrm{PDH})$, malate dehydrogenase, and IDH [14].

Upon exposure to free radicals and reactive oxygen species, mutation in $I D H$ gene alters the enzymatic property of $I D H 1$ and leads to increase conversion of alpha-ketogluterate to 2hydroxyglutarate $(2 \mathrm{HG})$ metabolite and decreased production of NADPH, and accordingly reduced glutathione. These alterations may raise the oxidative stress level in mutant IDH1 cells and acting as an oncogene [14], [18], [19].

Several studies suggest that $I D H 1$ mutations are an early event in glioma development [6]. IDH1 mutations are seen in a high percentage (50\%-93\%) of grade II and III astrocytomas and oligodendrogliomas and secondary GBM tumors [9], [14], [16], [20], [21], [22], [23]. Mutations in $\mathrm{IDH} 2$ have been found in fewer than $3 \%$ of glial tumors, mostly in oligodendroglial tumors [6], [21], [23]. IDH mutations are rare in primary glioblastoma [6], [14], [21].

In addition to the diagnostic value of $I D H 1 / 2$ mutations, they have been associated with a better outcome in patients with lowgrade diffuse gliomas, anaplastic astrocytomas, and glioblastomas and have shown to be a powerful independent prognostic factor for prolonged survival [6], [21], [24], [25], [26].

The aims of this study were to validate the frequency of IDH1 mutation in Iraqi patients in Baghdad city with gliomas by immunohistochemical study and to correlate IDHI positivity with certain clinicopathological variables.

\section{Patients, Materials and Methods}

\subsection{Patients and Materials}

This is a retrospective and prospective randomized study. In a period extended from October 2013- October 2016, 66 cases of intracranial gliomas of both gender and all age groups in the Baghdad city were included in this study. Formalin fixed, paraffin embedded brain excisional biopsies of the cases retrieved from the archival materials of a pathology laboratories of Neurosurgical hospitals in Baghdad (AlShaheid Ghazi Al-Hareri Teaching hospital and Neurosurgery Teaching hospital) and some private clinical laboratories.

In addition, ten normal of different age groups of brain tissue samples in form of paraffin blocks took from forensic medicine unit.

The clinical data of the patients including age and gender, radiological findings of site and side of affection and the provisional clinical diagnosis obtained from archival histological reports.

Hematoxylin and Eosin stained section from each case revised, concerning the pathological type and grade to prove the diagnosis of gliomas. The cases graded and classified according to WHO classification of the central nervous system tumors [5].

\subsection{Methods}

a. Tissue Microarray Technique (TMA):

This accomplished by using manual TMA kit. Manual TMA kit comprises two components (Moulder and Puncher extractor tool) [27]. In the TM procedure, a hollow needle used to cutting tissue cores as small as $2 \mathrm{~mm}$ in diameter from regions of concern, (areas of glial tumors that distinguished previously in (H \& E) staining slides) in paraffin-embedded tissues [27]. A microarray recipient's paraffin block contains 24 small cores of demonstrative tissue samples, each measure $2 \mathrm{~mm}$ in diameter. Sections from microarray block cut using a microtome, equestrian on a single microscope slide and then assessed by staining with $\mathrm{H}$ and $\mathrm{E}$ stain, then another sections made on 3-micron thickness for the immunohistochemical stain for IDH1 antibodies.

b. Immunohistochemical technique:

Dako automated Autostainer Link 48 with Dako EnVision $^{\mathrm{TM}}$ FLEX detection system used in immunohistochemistry work of the study [28].

Three-micron sections took from formalin fixed, paraffin embedded tissue blocks and mounted on Dako FLEX IHC slides, then allowed to fix overnight in oven at temperature $65^{\circ} \mathrm{C}$. Then performed Pre-treatment procedure, which recommended three in one specimen preparation procedure using PT Link: Deparaffinization, rehydration and heatinduced epitope retrieval (HIER) on the tissue sections. Prepared a working solution by diluting the EnVision ${ }^{\mathrm{TM}}$ FLEX Target Retrieval Solution concentrate 1:50 in distilled or deionized water then PT Link tanks filled with sufficient quantity $(1.5 \mathrm{~L})$ of working solution to cover the tissue sections. PT Link established, to pre-heat the solution to $65^{\circ} \mathrm{C}$. Immersed the mounted, formalin-fixed, paraffinembedded tissue sections into the pre-heated EnVision ${ }^{\mathrm{TM}}$ FLEX Target Retrieval Solution in PT Link tanks and incubate for 20 minutes at $97^{\circ} \mathrm{C}$ then the sections put to cool in PT Link to $65^{\circ} \mathrm{C}$ for 20 minutes. Each autostainer slide rack removed with the slides from the PT Link tank and immediately dip slides into a tank (PT Link Rinse Station, Code PT109) with diluted, room temperature EnVision ${ }^{\mathrm{TM}}$ FLEX Wash Buffer (20x). The slides placed in the diluted, room temperature EnVision ${ }^{\text {TM }}$ FLEX Wash Buffer (20x) for five minutes and sited them on a Dako Autostainer Link 48 and proceeded with staining. Staining procedure, Anti $I D H I$ antibody (IDH1 Polyclonal rabbit /IgG antibody catalog Number PA5-28206; manufactured by Thermo Fisher Scientific, USA) added in dilution 1:100 in autostainer system, the staining steps and incubation times are preprogrammed into the software of Dako 
Autostainer/Autostainer Plus instruments, using the protocols, Template protocol: FLEX_200 (200 $\mu \mathrm{L}$ dispense volume)

Auto programs for staining runs, FLEX_Mo (FLEX+ Mouse (LINKER) protocol) in $I D H 1$. The Auxiliary step should be set to "rinse buffer" in staining runs with $\leq 10$ slides. For staining runs with $\geq 10$ slides, the Auxiliary step should be set to "none". This ascertains comparable wash times. All incubation steps performed at room temperature. Regarding incubation times, for $I D H 1$ antibody it was 30 minutes. Finally, the sections lightly counterstained with hematoxylin, dehydrated and mounted. Negative control sections treated in the same way, but by the substitution of primary antibody with PBS. Positive control sections took from positive cases and performed in each batch of staining.

Positive results show strong cytoplasmic staining that appeared only in the tumor cells. Determination of $I D H 1$ positivity did by visual semi quantitative assessment of the proportion of the positively staining tumor cells. Cases with equal or more than $10 \%$ IDH1 expression considered as positive, while cases with less than $10 \%$ cells were negative [9], [29], [30].

Statistical analyses performed using SPSS statistical package for Social Sciences (version 17.0 for windows, SPSS, Chicago, IL, USA). As the data were qualitative. So relations analyzed by Chi square test. $\mathrm{P}$ value of less than or equal to 0.05 was considered statistically significant.

\section{Results}

\subsection{Clinical Analysis of the Samples}

During the period of one year, a total of (66) tissue samples in the form of paraffin blocks of brain gliomas specimens was included in this study. The patients' age range from (1-75) years, distribution among age groups revealed that the mean age of cases in this study was 38.41 , standard deviation $=18.15$ years and median of 37 years. Most of cases were in the third and fourth decades. There were $9(13.44 \%)$ pediatric patients and $57(86.36 \%)$ adults.

Thirty-four (51.51\%) were males and 32 (48.49\%) were females and the male to female ratio was 1.06:1.

\subsection{Histopathological Findings}

Histological examination of Hematoxylin and Eosin stain (H\&E) sections confirmed and grading was done to the cases according to the criteria established by WHO 2007. There were 2 cases WHO grade I (pilocytic astrocytomas and subependymal giant cell astrocytoma), 25 cases were WHO grade II (11 cases were diffuse astrocytoma, 1 case was pleomorphic xanthoastrocytoma, 2 cases were ependymoma and 11 cases were oligodendroglioma), 16 cases were WHO grade III ( 7 cases were anaplastic astrocytoma, 5 cases were anaplastic oligodendroglioma and 4 cases were mixed anaplastic oligoastrocytoma) and 23 cases were WHO grade IV glioblastoma (15 cases were primary glioblastoma and 8 cases were secondary glioblastoma).

\subsection{IDH1 Immunohistochemical Expression in Gliomas}

Positive cytoplasmic IDH1 staining was found in 38 $(57.6 \%)$ of cases of glioma. This positive staining was appear only in tumor cells and not shown in normal brain tissue cases.

Table 1. IDH1 status and the types of gliomas.

\begin{tabular}{|c|c|c|c|c|c|}
\hline & & & \multicolumn{2}{|c|}{ IDH1 (IHC) } & \multirow{2}{*}{ Total } \\
\hline & & & Positive & Negative & \\
\hline \multirow{22}{*}{ Types of Glioma } & \multirow{2}{*}{ Subependymal giant cell astrocytoma } & Count & 0 & 1 & 1 \\
\hline & & $\%$ & $0.0 \%$ & $100.0 \%$ & $100.0 \%$ \\
\hline & \multirow{2}{*}{ Pilocytic astrocytoma } & Count & 0 & 1 & 1 \\
\hline & & $\%$ & $.0 \%$ & $100.0 \%$ & $100.0 \%$ \\
\hline & \multirow{2}{*}{ Diffuse astrocytoma } & Count & 8 & 3 & 11 \\
\hline & & $\%$ & $72.72 \%$ & $27.28 \%$ & $100.0 \%$ \\
\hline & \multirow{2}{*}{ Ependymoma } & Count & 0 & 2 & 2 \\
\hline & & $\%$ & $0 \%$ & $100.0 \%$ & $100.0 \%$ \\
\hline & \multirow{2}{*}{ Pleomorphic xanthastrocytoma } & Count & 0 & 1 & 1 \\
\hline & & $\%$ & $.0 \%$ & $100.0 \%$ & $100.0 \%$ \\
\hline & \multirow{2}{*}{ Oligodendroglioma } & Count & 9 & 2 & 11 \\
\hline & & $\%$ & $81.8 \%$ & $18.2 \%$ & $100.0 \%$ \\
\hline & \multirow{2}{*}{ Anaplastic astrocytoma } & Count & 3 & 4 & 7 \\
\hline & & $\%$ & $42.86 \%$ & 57.14 & $100.0 \%$ \\
\hline & \multirow{2}{*}{ Anaplastic oligodendroglioma } & Count & 4 & 1 & 5 \\
\hline & & $\%$ & $80.0 \%$ & $20.0 \%$ & $100.0 \%$ \\
\hline & \multirow{2}{*}{ Anaplastic oligoastrocytoma } & Count & 3 & 1 & 4 \\
\hline & & $\%$ & $75.0 \%$ & $25.0 \%$ & $100.0 \%$ \\
\hline & \multirow{2}{*}{ Primary glioblastoma } & Count & 4 & 11 & 15 \\
\hline & & $\%$ & $26.7 \%$ & $73.3 \%$ & $100.0 \%$ \\
\hline & \multirow{4}{*}{ Secondary glioblastoma } & Count & 7 & 1 & 8 \\
\hline & & $\%$ & $87.5 \%$ & $12.5 \%$ & $100.0 \%$ \\
\hline \multirow{2}{*}{ Total } & & Count & 38 & 28 & 66 \\
\hline & & $\%$ & $57.6 \%$ & $42.4 \%$ & $100.0 \%$ \\
\hline
\end{tabular}

$\mathrm{X}^{2}$ test, $P<0.033 \mathrm{~S}$ 
a. $I D H 1$ status and the pathological types of glioma: The secondary glioblastoma, Oligodendroglial tumors (oligodendroglioma, anaplastic oligodendroglioma and anaplastic oligoastrocytoma) and diffuse astrocytoma represent the largest groups of $I D H 1$ positivity, $(87 \%, 80 \%$ and $72.72 \%$ respectively) followed by anaplastic astrocytoma $(42 \%)$, then primary glioblastoma (26\%). The difference between the frequency of different pathological types of gliomas and IDHI positivity is statistically significant, ( $p$ $<0.033$ ). (Table 1).

b. Concerning the grades of gliomas, although IDH1 expression was high in grades (II, III) $(66 \%)$ in compares to grades (I, IV) (44\%), no significant relationship was identified between the grades of tumors and positivity of IDH1 $(P=0.183)$. (Table 2).

Table 2. Correlation of IDH1 positivity and the grades of gliomas.

\begin{tabular}{|c|c|c|c|c|c|}
\hline & & & \multicolumn{2}{|c|}{ IDH1 (IHC) } & \multirow{2}{*}{ Total } \\
\hline & & & Positive & Negative & \\
\hline \multirow{8}{*}{ Grade } & \multirow{2}{*}{ I } & Count & 0 & 2 & 2 \\
\hline & & $\%$ & $.0 \%$ & $100.0 \%$ & $100.0 \%$ \\
\hline & \multirow{2}{*}{ II } & Count & 17 & 8 & 25 \\
\hline & & $\%$ & $68.0 \%$ & $32.0 \%$ & $100.0 \%$ \\
\hline & \multirow{2}{*}{ III } & Count & 10 & 6 & 16 \\
\hline & & $\%$ & $62.5 \%$ & $37.5 \%$ & $100.0 \%$ \\
\hline & \multirow{2}{*}{ IV } & Count & 11 & 12 & 23 \\
\hline & & $\%$ & $47.8 \%$ & $52.2 \%$ & $100.0 \%$ \\
\hline \multirow{2}{*}{ Total } & & Count & 38 & 28 & 66 \\
\hline & & $\%$ & $57.6 \%$ & $42.4 \%$ & $100.0 \%$ \\
\hline
\end{tabular}

$\mathrm{X}^{2}$ test, $P=0.183 \mathrm{NS}$.

\section{c. Age:}

Regarding adult and pediatric glioma case, thirty six cases of adult gliomas were showing IDHI positivity (IDHI expression was seen predominantly in young and middle ages patients, $\{20-40$ years $\}$ ) while, two cases of pediatric gliomas which were IDH1 positive (one was 7 years old and diagnosed as anaplastic oligodendroglioma and the other was primary GBM was 17 years old). There was statistical significant association identified between IDH1 expression and adult and pediatric gliomas. $P<0.02$. (Table 3 ).

Table 3. Distribution of IDH1 positivity and the age related Gliomas.

\begin{tabular}{llllll}
\hline & & & \multicolumn{2}{l}{ IDH1 (IHC) } & \multirow{2}{*}{ Total } \\
\cline { 3 - 5 } & & & Positive & Negative & \\
\hline \multirow{3}{*}{ Age } & $<18$ & Count & 2 & 7 & 9 \\
group & year & $\%$ & 22.2 & $77.8 \%$ & $100.0 \%$ \\
& $>=18$ & Count & 36 & 21 & 57 \\
\multirow{2}{*}{ Total } & year & $\%$ & $63.1 \%$ & $36.9 \%$ & $100.0 \%$ \\
& & Count & 38 & 28 & 66 \\
& & $\%$ & $57.6 \%$ & $42.4 \%$ & $100.0 \%$ \\
\hline
\end{tabular}

$\mathrm{X}^{2}$ test, $P<0.02 \mathrm{~S}$

d. Gender, $I D H 1$ evenly expressed in both sexes, nineteen cases were positive for each gender. No significant relationship found in association between $I D H 1$ positivity and gender whether male or female. $(\mathrm{P}=0,774)$. (Table 4).
Table 4. Distribution of IDH1 positivity and gender related gliomas.

\begin{tabular}{llllll}
\hline & & \multicolumn{3}{l}{ IDH1 (IHC) } & \multirow{2}{*}{ Total } \\
\hline \multirow{3}{*}{ Gender } & & & Positive & Negative & \\
\cline { 3 - 5 } & \multirow{2}{*}{ Male } & Count & 19 & 15 & 34 \\
& & $\%$ & $55.8 \%$ & $44.2 \%$ & $100.0 \%$ \\
\multirow{3}{*}{ Total } & Female & Count & 19 & 13 & 32 \\
& & $\%$ & $59.37 \%$ & $40.63 \%$ & $100.0 \%$ \\
& & Count & 38 & 28 & 66 \\
\hline
\end{tabular}

$\mathrm{X}^{2}$ test, $P=0.774$

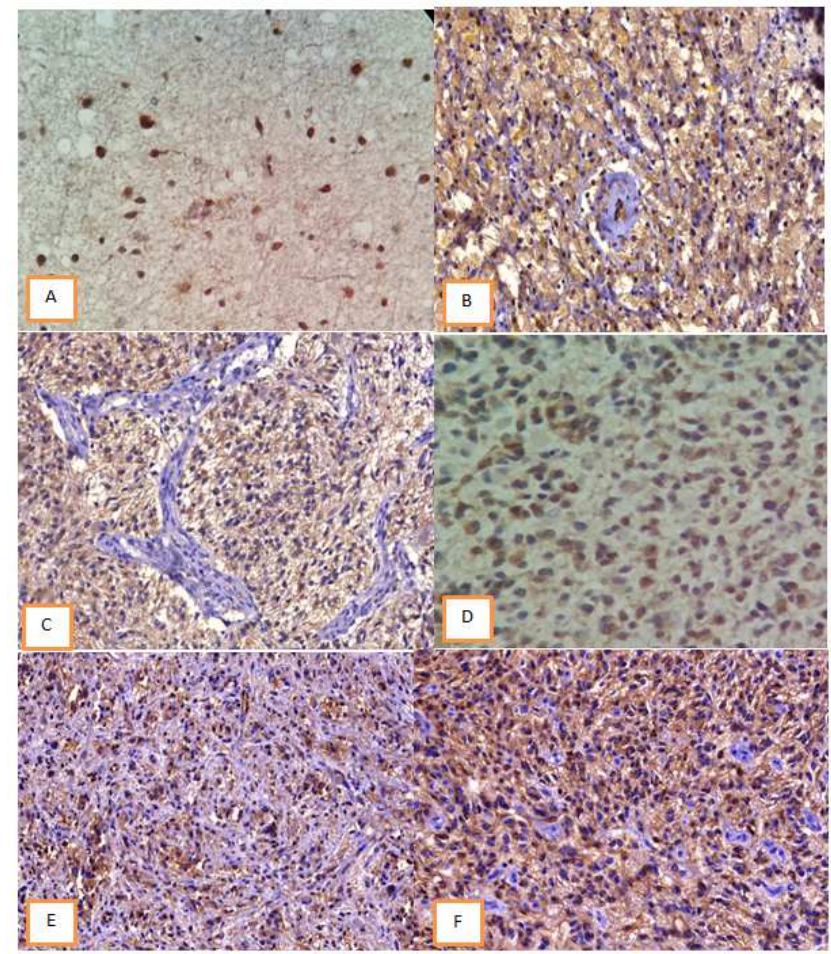

Figure 1. Positive brown cytoplasmic IDH1 staining. A- Low grade diffuse astrocytoma.(IDH1 x400). B- Secondary glioblastoma (IDH1 x200). CGlioblastoma (IDH1 x200). D- Anaplastic astrocytoma (IDH1 x400). EOligodendroglioma (IDH1 x200). F- Anaplastic oligoastrocytoma (IDH1 $x 200)$.

\section{Discussion}

IDH1 mutation has become as a main diagnostic and prognostic biomarker for gliomas [6], [30]. In line with many previous studies, that reported a higher frequency of $I D H 1$ in low grade diffuse astrocytoma, oligodendroglial tumors, anaplastic astrocytoma and secondary glioblastoma in compare with primary glioblastoma and other pathological types [20], [29], [31], [32], [33], [34], [35]. The current study showed highest $I D H 1$ positivity among diffuse astrocytomas $(72.72 \%)$, oligodendrogliomas $(81.8 \%)$ and secondary glioblastoma $(87.5 \%)$, there was significant association between expression of $I D H 1$ and pathological types of gliomas.

In contrast to the majority of the previous studies [18], [20], [21], [29], [31], [33], [35], [36], [37], [38], [39]. The present study clarified a relatively higher degree of $I D H 1$ expression in primary glioblastoma $(26.7 \%)$. This may be 
due to ambiguous presentation, delay diagnosis and treatment of some of low grade gliomas that presented initially as primary glioblastomas [29]. Nobusawa proposed that these primary glioblastomas with $I D H 1$ mutation actually represent secondary glioblastomas with an unusually short clinical presentation [40]. In the current study association of IDHI mutation statistically correlated with secondary glioblastoma, and this agree with Watanabe et al and Nobusawa studies that considered $I D H 1$ mutation as a most reliable genetic marker of secondary but not primary glioblastomas [20], [40].

IDH1 mutation was highly expressed in low grade astrocytomas and oligodendrogliomas (grade II 68\%) in compare with other grades; this clue confirms the neoplastic nature of the lesions and aids to differentiate the lesser cellular infiltrative tumor and /or tumor margin from gliosis mostly in a stereotactic biopsy [41], [42], [43], [44], [45]. As IDH1 mutation is not institute in non-neoplastic surroundings that can histologically simulator to gliomas (for example; oversensitive gliosis, radiation deviations, viral infections, infarcts, demyelinating situations, etc), allowing for improved diagnostic precision of suboptimal brain biopsies [45], [46], also in this study IDH1 mutation did not articulated in normal brain tissue.

In opposing to adult gliomas, pediatric low and high grade gliomas did not express $I D H I$. There was only one adolescent primary glioblastoma and a pediatric anaplastic oligodendroglioma, which expressed the IDH1 mutation. Therefore, there was a statically correlation between adult and pediatric gliomas although $I D H 1$ highly expressed in young and middle age patients. This is in agreement with other related studies [20], [26], [29], [47], [48], [49], [50], which established no role of $I D H 1$ mutation in pediatric gliomas. This explained by the frequency, pathological spectrum and the anatomical location of gliomas in this age group.

Pollack et al examined IDHI mutations in pediatric primary glioblastoma and concluded that; IDH1 mutations are common in malignant gliomas in older children, suggesting that a subset of these lesions may be biologically similar to malignant gliomas arising in younger adults and may be associated with a more favorable prognosis [47].

Regarding gender, although gliomas occur more common in male gender, $I D H 1$ expression was approximately equally between both male and female, with no gender predilection, this was agree with Saeed MS [29].

The fact that IDH1 mutation was recognized in both oligodendroglial and astrocytic tumors recommends that, they may have a common cell of origin, IDH1 mutation in oligodendrogliomas frequently coexist with $1 \mathrm{p} / 19 \mathrm{q}$ codeletion and in astrocytomas with TP53 mutations, this also explain $I D H 2$ mutation is an early event in the devotement of astrocytomas and oligodendroglioma [29].

IDH1 mutation proved by many studies as associated with prolonged survival, so $I D H$ mutated tumors are associated with a more favorable prognosis. Additionally, patients with IDH mutant glioblastomas showed longer survival than patients with glioblastomas, or even anaplastic astrocytomas, without $I D H$ mutations [21], [24], [25], [51], [52], [53], [54].

\section{Conclusions}

IDH1 mutation is universally present in adult gliomas mainly low grade gliomas, and secondary glioblastoma, with no sex predilection, but it has no role in pediatric gliomas. It could be a diagnostic and prognostic marker in adult glial tumors.

\section{References}

[1] Schwartzbaum JA, Fisher JL, Aldape KD, Wrensch M. Epidemiology and molecular pathology of glioma. Nature Clinical Practice Neurology. 2006; 2 (9): 494-503.

[2] Ostrom QT, Bauchet L, Davis FG, Deltour I, Fisher JL, Langer ChE, et al. The epidemiology of glioma in adults: a "state of the science" review. Neuro-Oncology. 2014; 16 (7): 896-913.

[3] Kumar V, Abbas AK, Aster J. Central Nervous System. In: Robbin's basic pathology, $9^{\text {th }}$ edition. Elsevier/ Philadelphia, 2013; p842.

[4] Louis DN, Perry A, Reifenberger G, Deimling AV, FigarellaBranger D, Cavenee WK, et al. The 2016 World Health Organization Classification of Tumors of the Central Nervous System: a summary. Acta Neuropathol. 2016; 131: 803-820.

[5] Louis DN, Ohgaki H, Wiestler OD, Cavenee WK, Burger PC, Jouvet A, et al. The 2007 WHO Classi Wcation of Tumours of the Central Nervous System. Acta Neuropathol. 2007; 114: 97-109.

[6] Nikiforova MN, Hamilton RL. Molecular Diagnostics of Gliomas. Arch Pathol Lab Med. 2011; 135: 558-568.

[7] Xia L, Wu B, Fu Z, Feng F, Qiao E, Li Q, et al. Prognostic role of IDH mutations in gliomas: a meta-analysis of 55 observational studies. Oncotarget 2015; 6 (19): 17354-17365.

[8] Jansen M, Yip S, Louis DN. Molecular pathology in adult neuro-oncology: an update on diagnostic, prognostic and predictive markers. Lancet Neurol. 2010; 9 (7): 717-726.

[9] Balss J, Meyer J, Mueller W, Korshunov A, Hartmann C, and Von Deimling A. Analysis of the IDHI codon 132 mutation in brain tumor. Act Neuropathol. 2008; 116: 597-602.

[10] Ellison D, Love S, Chimelli L, et al. Astrocytic neoplasms. In: Neuropathology, A reference text of CNS pathology, third edition. Elsevier Inc., Italy, 2013; pp 705-28.

[11] Thon N, Eigenbrod S, Grasbon-Frodl EM, et al. Novel molecular stereotactic biopsy procedures reveal intratumoral homogeneity of loss of heterozygosity of $1 p / 19 q$ and TP53 mutations in World Health Organization grade II gliomas. J Neuropathol Exp Neurol. 2009; 68 (11): 1219-1228.

[12] https://www.ncbi.nlm.nih.gov/gene?term=3417 Last update: 16-Jul-2017 Last accessed 70/7/2017.

[13] Lee SM, Koh HJ, Park DC, et al. Cytosolic NADP(+)dependent isocitrate dehydrogenase status modulates oxidative damage to cells. Free Radic Biol Med. 2002; 32 (11): 1185-96.

[14] Cohen A, Holmen Sh, Colman H. IDH1 and IDH2 Mutations in Gliomas. Curr Neurol Neurosci Rep. 2013; 13 (5): 345. 
[15] Kloosterhof NK, Bralten LB, Dubbink HJ, French PJ, van den Bent MJ. Isocitrate dehydrogenase-1 mutations: a fundamentally new understanding of diffuse glioma? Lancet Oncol. 2011; 12 (1): 83-91.

[16] Sonoda Y, Kumabe T, Nakamura T, Saito R, Kanamori M, Yamashita Y, et al. Analysis of IDH1 and IDH2 mutations in Japanese glioma patients. Cancer Science. 2009; 100: 19961998.

[17] Pollard PJ, Ratcliffe PJ. Cancer. Puzzling patterns of predisposition. Science. 2009; 324 (5924): 192-4.

[18] Capper D, WeiBert S, Balss J, Habel A, Meyer J, Jaer D, et al. Characterization of R132H Mutation-specific IDH1 Antibody Binding in Brain Tumors. Brain Pathol. 2010; 20; 245-254.

[19] Guo Ch, Pirozzi ChJ, Lopez GY, Yan H. Isocitrate dehydrogenase mutations in gliomas: mechanisms, biomarkers and therapeutic target. Curr Opin Neurol. 2011 December; 24 (6): 648-652.

[20] Watanabe T, Nobusawa S, Kleihues P, and Ohgaki H. IDHI mutations are early events in the development of astrocytomas and oligodendrogliomas. Am J Pathol. 2009; 174: 1149-1153.

[21] Yan H, Parsons DW, Jin G, McLendon R, Rasheed BA, Yuan $\mathrm{W}$, et al. IDH1 and IDH2 mutations in gliomas. N Engl J Med. 2009; 360: 765-773.

[22] Kang MR, Kim MS, Oh JE, et al. Mutational analysis of IDH1 codon 132 in glioblastomas and other common cancers. Int J Cancer 2009; 125: 353-5.

[23] Yan H, Bigner DD, Velculescu V, Parsons DW. Mutant Metabolic Enzymes Are at the Origin of Gliomas. Cancer Res 2009; 69 (24): 9157-9.

[24] Parsons DW, Jones S, Zhang X, et al. An integrated genomic analysis of human glioblastoma multiforme. Science. 2008; 321 (5897): 1807-1812.

[25] Van den JM, Dubbink HJ, Marie Y, Brandes AA, Taphoorn MJB, Wesseling P, et al. IDH1 and IDH2 Mutations Are Prognostic but not Predictive for Outcome in Anaplastic Oligodendroglial Tumors: A Report of the European Organization for Research and Treatment of Cancer Brain Tumor Group. Clin Cancer Res 2010; 16 (5): 1597-604.

[26] Hartmann C, Meyer J, Balss J, et al. Type and frequency of IDH1 and IDH2 mutations are related to astrocytic and oligodendroglial differentiation and age: a study of 1010 diffuse gliomas. Acta Neuropathol. 2009; 118: 469-474.

[27] http://www.3dhistech.com/TMA.

[28] http://www.agilent.com/en/products/immunohistochemistry/

[29] Saeed MS. IDH1 Mutation in Gliomas in Mosul City - Iraq. OA Maced J Med Sci. 2015 Jun 15; 3 (2): 250-255.

[30] Sanson M, Marie Y, Paris S, Idbaih A, Laffaire J, Ducrary F, et al. Isocitrate dehydrogenase 1 codon 132 mutation is an important prognostic biomarker in gliomas. J Clin Oncol. 2009; 27: 4150-4154.

[31] Ichimura K, Pearson DM, Kocialkowski S, Bucklund LM, Chan R, Jones DTW, et al. IDH1 mutations are present in the majority of common adult gliomas but rare in primary glioblastomas. Neuro-Oncology 2009; 11: 341-347.

[32] Daniel J. et al. Comprehensive, Integrative Genomic Analysis of Diffuse Lower-Grade Gliomas The Cancer Genome Atlas Research Network. N Engl J Med 2015; 372: 2481-98.

[33] Takano S, Kato Y, Yamamoto T, Kaneko MK, Ishikawa E, Tsujimoto Y, et al. Immunohistochemical detection of IDHI mutation, $\mathrm{p} 53$, and internexin as prognostic factors of glial tumors. J Neurooncol. 2012; 108 (3): 361-373.

[34] Karsy M, Guan J, Cohen AL, Jensen RL, Colman H. New Molecular Considerations for Glioma: IDH, ATRX, BRAF, TERT, H3 K27M. Current Neurology and Neuroscience Reports 2017; 17: 19.

[35] Labussiere M, Marc SM, Idbaih A and Delattre JY. IDHI Gene Mutations: A New Paradigm in Glioma Prognosis and Therapy? The Oncologist. 2010; 15; 196-199.

[36] Leibetseder A, Ackerl MM, Flechl B, Wöhrer A, Widhalm G, Dieckmann K. Outcome and molecular characteristics of adolescent and young adult patients with newly diagnosed primary glioblastoma: a study of the Society of Austrian Neurooncology (SANO). Neuro Oncol. 2013; 15 (1): 112-121.

[37] Dimitrov L, Hong ChS, Yang Ch, Zhuang Z, Heiss JD. New Developments in the Pathogenesis and Therapeutic Targeting of the IDH1 Mutation in Glioma. Int. J. Med. Sci. 2015; 12 (3): 201-213.

[38] Toedt G, Barbus S, Wolter M, Felsberg J, Tews B, Blond F, et al. Molecular signatures classify astrocytic gliomas by $\mathrm{IDHI}$ mutation status. Int J Cancer. 2011; 128: 1095-1103.

[39] Jha P, Suri V, Sharma V, Singh G, Sharma MC, Pathak p et al. IDH1 mutations in gliomas: First series from a tertiary care centre in India with comprehensive review of literature. Exper Mol Pathol. 2011; 91: 385-393.

[40] Nobusawa S, Watanabe T, Kleihus P, et al. IDH1 mutation as molecular signature and predictive factor of secondary glioblastomas. Clin Cancer Res. 2009; 15: 6002-6007.

[41] Hartmann C, Meyer J, Balss J, et al. Type and frequency of IDH1 and IDH2 mutations are related to astrocytic and oligodendroglial differentiation and age: a study of 1010 diffuse gliomas. Acta Neuropathol. 2009; 118: 469-474.

[42] Rivera-Zengotita M, and Yachnis AT. Gliosis versus glioma? Don't grade until you know. Adv Anat Pathol. 2012; 19 (4): 239-249.

[43] Camelo-Piragua S, Jansen M, Ganguly A, Kim JC, Louis DN, and Nutt CL. Mutant IDH1-specific immunohisochemistry distinguishes diffuse astrocytoma from astrocytosis. Act Neuropathol. 2010; 119: 509-511.

[44] Ohgaki H, and Kleihues P, Genetic profile of astrocytic and oligodendroglial gliomas. Brain Tumor Pathol. 2011; 28 (3): 177-183.

[45] Capper D, Sahm F, Hartmann C, Meyermann R, von Deimling A, Schittenhelm J. Application of mutant IDH1 antibody to differentiate diffuse glioma from nonneoplastic central nervous system lesions and therapy-induced changes. Am J Surg Pathol. 2010; 34 (8): 1199-1204.

[46] Horbinski C, Kofler J, Kelly LM, Murdoch GH, Nikiforova MN. Diagnostic use of IDH1/2 mutation analysis in routine clinical testing of formalin-fixed, paraffin-embedded glioma tissues. J Neuropathol Exp Neurol. 2009; 68 (12): 13191325 . 
[47] Pollack IF, Hamilton RL, Sobol RW, Nikiforova MN, LyonsWeiler MA, La Framboise WA et al. IDH1 mutations are common in malignant gliomas arising in adolescent: a report from the Children's Oncology Group. Childs Nerv Syst. 2011; 27 (1): 87-94.

[48] Antonelli M, Buttarelli FR, Arcella A, et al. Prognostic significance of histological grading, p53 status, YKL-40 expression, and $I D H 1$ mutations in pediatric high-grade gliomas. J Neurooncol. 2010 Sep; 99 (2): 209-15.

[49] Korshunov A, Meyer J, Capper D, Christians A, Remke M, Witt $\mathrm{H}$, et al. Combined molecular analysis of BRAF and IDH1 distinguishes pilocytic astrocytoma from diffuse astrocytoma. Acta Neuropathol. 2009; 118: 401-405.

[50] Paugh BS, Qu C, Jones C, Liu Z, Adamowicz-Brice M, Zhang $\mathrm{J}$, et al. Integrated molecular genetic profiling of pediatric high-grade gliomas reveals key differences with the adult disease. J Clin Oncol. 2010; 28: 3061-3068.
[51] R. Stupp, M. Brada, M. J. van den Bent, J.-C. Tonn \& G. Pentheroudakis. High-grade glioma: ESMO Clinical Practice Guidelines for diagnosis, treatment and follow-up. Annals of Oncology 2014; 25 (3): iii93-iii101.

[52] Tareq A. Juratli TA, Kirsch M, Robel K, Soucek S, Geiger K, et al. IDH mutations as an early and consistent marker in lowgrade astrocytomas WHO grade II and their consecutive secondary high-grade gliomas. J Neurooncol 2012; 108: 403410 .

[53] Beiko J, Suki D, Hess KR, Fox BD, Cheung V, Cabral M, et al. IDH1 mutant malignant astrocytomas are more amenable to surgical resection and have a survival benefit associated with maximal surgical resection. Neuro-oncology 2014; 16 : 81-91.

[54] SongTao Q, Lei Y, Si G, YanQing D, HuiXia H, XueLin Z, et al. IDH mutations predict longer survival and response to temozolomide in secondary glioblastoma. Cancer science. 2012; 103: 269-73. 